American Journal of Applied Sciences 4 (5): 328-332, 2007

ISSN 1546-9239

(C) 2007 Science Publications

\title{
Comparative Study of Clinker's Transformation at Different Temperature Zone During Cement Production
}

\author{
${ }^{1}$ Mohd Sobri Idris, ${ }^{2}$ Khairul Nizar Ismail, ${ }^{1}$ Shamsul Baharin Jamaludin, ${ }^{1}$ Che Mohd Ruzaidi Ghazali \\ and ${ }^{1}$ Kamarudin Hussin \\ ${ }^{1}$ School of Materials Engineering and ${ }^{2}$ School of Environmental Engineering \\ University Malaysia Perlis (UNIMAP), PO Box 17, Pejabat Pos Kangar, 01007, Kangar, Perlis, Malaysia
}

\begin{abstract}
Chemical composition analysis using x-ray fluorescence is one of the important quality analysis for examining of cement and widely used in cement industries for a long time as a tool to estimate phase composition. X-ray diffraction is one of the established techniques as a qualitative tool to identify phase existing in the sample. This study will discuss about the correlation between quantitative and qualitative analyses in order to understand phase transformation in production of cement. Qualitative analysis had revealed a lot of information which could not be identified by using $\mathrm{x}$-ray fluorescence especially polymorphisms existed in the clinker samples.
\end{abstract}

Keywords: Clinker, x-ray diffraction, phase analysis

\section{INTRODUCTION}

Portland cement is made by heating a mixture of limestone and clay, or other materials of similar composition to a temperature of about $1450^{\circ} \mathrm{C}$. Partial fusion occurs and nodules of clinker are produced. The clinker is mixed with a few per cent of calcium sulphates and finely ground, to produce cement ${ }^{[1]}$. More than 95 wt.\% of ordinary Portland cement clinker consists of $\mathrm{CaO}, \mathrm{SiO}_{2}, \mathrm{Al}_{2} \mathrm{O}_{3}$ and $\mathrm{Fe}_{2} \mathrm{O}_{3}$. These four oxides form the main phases in clinker: alite $\left(\mathrm{Ca}_{3} \mathrm{SiO}_{5}\right)$, belite $\left(\mathrm{Ca}_{2} \mathrm{SiO}_{4}\right)$, aluminate $\left(\mathrm{Ca}_{3} \mathrm{Al}_{2} \mathrm{O}_{6}\right)$ and ferrite $\left(\mathrm{Ca}_{2} \mathrm{AlFeO}_{5}\right)^{[2]}$. These oxides must be in the right percentage in order to achieve standard quality of cement.

One of the important quality parameters of Portland cement is its chemical and phase composition. It is necessary to determine a complete mineralogy of clinker cement to correctly understand, interpret and predict the outcome of any plant production process. The cement industry's standard method (ASTM C 150) used in quantitative phase analysis of alite, belite, aluminate and ferrite has long time been known to provide approximate concentrations ${ }^{[3]}$. XRF is widely used in the cement industry, requires limited sample preparation and is very reliable and cost-effective. Quantitative analysis was used to identify chemical content present in samples and mineral contents were calculated by using Bogue calculation. In 1929, Bogue introduced a method for estimating Portland cement's compound composition from its chemical analysis. The Bogue calculation has been the standard method used by the cement industry (ASTM C 150) ${ }^{[4]}$.

X-ray diffraction (XRD) has been used for a long time as a complementary tool, able to provide information on the nature and possibly quantify the polymorphs. But, until the recent introduction of tractable computers and software, only specialists in their laboratories used this method, with good results. The XRD quantitative analysis was mainly used the internal standard method. A major difficulty arises from the high degree of overlapping of the Bragg peaks in the powder patterns of the major phases. It reduces the domain of applicability of the traditional XRD peak area measurement, based on integrated intensity ratios $^{[5]}$.

In order to understand phase transformation of mineral phases in clinker, a feasibility study was carried out for four samples of clinker from different sampling area in kiln. Quantitative and qualitative analyses had done to understand correlation between phase estimation using Bogue calculation and mineral phase existing in the samples.

\section{MATERIALS AND METHODS}

The clinker samples were supplied by Cement Industries of Malaysia Limited (CIMA Limited) located

Corresponding Author: Mohd Sobri Idris, School of Materials Engineering, University Malaysia Perlis (UNIMAP), PO Box 17, Pejabat Pos Kangar, 01007, Kangar, Perlis, Malaysia, Tel: +604-9798648, Fax: +604-9798178, 328 
at Bukit Keteri, Perlis, Malaysia. The samples were taken from a various place in kiln that have different section of temperature zone during production of cement. The samples were taken from four sections, which are section A (15 meter from end of kiln), section B (10 meter from end of kiln), section C (5 meter from end of kiln) and section $\mathrm{D}$ (at the end of kiln). Each sample was divided into three for different analysis. Samples were prepared according to ASTM procedure before investigated using Philips x-ray fluorescence to analyse chemical composition and x-ray diffraction Shimadzu LabX-6000 for phase identifications. Phase identification was performed using software Search Match ${ }^{\circledR}$ Ver. 3.01 from Shimadzu Corporation and PDF Database File version 2003 from ICDD.

\section{RESULTS AND DISCUSSION}

Table 1 shows the chemical composition of the samples analyzed by XRF. The main chemical composition of clinker had contributed to formation of major mineral phases like $\mathrm{Ca}, \mathrm{Si}, \mathrm{Al}$ and $\mathrm{Fe}$. These four major elements must be in the right composition range to ensure transformation of mineral can be established and in the acceptable range. According to Table 1, the highest composition $\mathrm{CaO}$ occurs in the sample $\mathrm{D}$ which is $63.4 \%$ and the lowest composition occur in the sample A $(61.18 \%)$. But the highest composition of $\mathrm{SiO}_{2}$ occurs in sample $\mathrm{A}(23.30 \%)$ and which is contradict with composition of $\mathrm{CaO}$. While composition of $\mathrm{Al}_{2} \mathrm{O}_{3}$ and $\mathrm{Fe}_{2} \mathrm{O}_{3}$ slightly increasing gradually from sample $\mathrm{A}$ until reached a peak at sample $\mathrm{C}$ and dropped a little in the sample D.

$\mathrm{CaO}$ is major elements which influence the formation of all phases in the clinker. Chemical reaction between $\mathrm{CaO}$ and $\mathrm{SiO}_{2}$ will produce alite $\left(\mathrm{Ca}_{3} \mathrm{SiO}_{5}\right)$ and belite $\left(\mathrm{Ca}_{2} \mathrm{SiO}_{4}\right)$ mineral phases which constitutes major phases in clinker. Reaction between $\mathrm{CaO}$ and $\mathrm{Al}_{2} \mathrm{O}_{3}$ will produce aluminate $\left(\mathrm{Ca}_{3} \mathrm{Al}_{2} \mathrm{O}_{6}\right)$ mineral phases and reaction between $\mathrm{CaO}-\mathrm{Al}_{2} \mathrm{O}_{3}-\mathrm{Fe}_{2} \mathrm{O}_{3}$ will produce ferrite $\left(\mathrm{Ca}_{2} \mathrm{AlFeO}_{5}\right)$. According to Hills (2001), during burning process at early stage of clinkering process (as we expected in section A), belite minerals identified as a dominant phases but there is still have other minor mineral phases such as alite, aluminate and ferrite. A reaction between $\mathrm{CaO}-\mathrm{SiO}_{2}-$ $\mathrm{Al}_{2} \mathrm{O}_{3}-\mathrm{Fe}_{2} \mathrm{O}_{3}$ depends on temperature and condition of reaction. This belite mineral phases as example will transform to $\alpha$-belite, $\beta$-belite and finally converted to alite at high temperature within suitable condition.

From the chemical composition identified such as in Table 1, potential reaction and mineral phases formed in the clinker will be estimated by using Bogue calculation. Table 1 shows the estimation of mineral phases in clinker from samples A, B, C and D. From the Table 2, it showed that the estimation of alite mineral phases $\left(\mathrm{C}_{3} \mathrm{~S}\right)$ in sample $\mathrm{A}$ is approximately $24.36 \%$ and that value increased moderately in sample B, C and has reaching a peak at sample $\mathrm{D}$ which is $48.32 \%$. Meanwhile, belite mineral phases $\left(\mathrm{C}_{2} \mathrm{~S}\right)$ also show the exponentially increment from sample A (8.61\%) to sample B (30.40\%) and reach a peak in sample C $(33.92 \%)$ before dropped by approximately $8 \%$ in sample D $(25.65 \%)$. In contrast, estimation composition of aluminate $\left(\mathrm{C}_{3} \mathrm{~A}\right)$ and ferrite mineral phases $\left(\mathrm{C}_{4} \mathrm{AF}\right)$ recorded highest in sample A rather than other samples. These two phases estimated $10.59 \%$ and $28.58 \%$ of phases in sample A respectively, while; these two phases remained constant in other samples.

Figure 1 shows the results of mineral phases in the four samples analysed by using x- ray diffraction. Even though, this analysis could not show the composition of mineral phases present in the samples, however it can confirm for that mineral phases present in the samples. Generally, the diffraction patterns represent the certain phase existed in the sample.

When a higher concentration of specific phase is scanned through x-ray diffraction, the intensity of specific angle will be increased. Specific information from each diffraction angle occurs in the XRD pattern could be revealed using Rietveld Analysis approach which is not specifically studied in this research. Figure 1 shows the diffraction of four samples analysed by XRD and phase identifications had done using software Search Match ${ }^{\circledR}$ Ver. 3.01 from Shimadzu Corporation.

From the Fig. 1, obviously all the mineral phases existed in the sample are identified. Figure 2 shows the diffraction peak for angle range $28^{\circ}-31^{\circ}$. Diffraction pattern at the angle $2 \theta \approx 29^{\circ}$ shows the mineral phase for aluminate indicated by PDF No. (23-0105) and (251456). Aluminate has hexagonal structure. Furthermore, $\gamma$-belite mineral phase which possess an orthorhombic structure also can be observed in this angle of diffraction with PDF No. (24-0034). There is increasing of intensity of peak at diffraction angle $2 \theta \approx 29^{0}$ started from sample B to sample D while sample A and sample $\mathrm{B}$ are constant respectively.

While, diffraction pattern at the angle $2 \theta \approx 30^{\circ}$ indicating the diffraction angle for two minor mineral phases which are aluminate and ferrite. Aluminate mineral phases identified are indicated by PDF No. (251456), (23-0105), (26-0559). Aluminate has same crystal structure which is hexagonal. While, ferrite with PDF No. is (25-0143) has a monoclinic crystal structure. This peak approximately same for all samples. 
Am. J. Applied Sci., 4 (5): 328-332, 2007

Table 1: Chemical composition of Clinker samples

\begin{tabular}{|c|c|c|c|c|c|c|c|c|c|c|c|}
\hline \multirow[t]{2}{*}{ Samples } & \multicolumn{11}{|c|}{ Chemical composition (weight percent) } \\
\hline & $\mathrm{SiO}_{2}$ & $\mathrm{Al}_{2} \mathrm{O}_{3}$ & $\mathrm{Fe}_{2} \mathrm{O}_{3}$ & $\mathrm{CaO}$ & $\mathrm{MgO}$ & $\mathrm{SO}_{3}$ & $\mathrm{P}_{2} \mathrm{O}_{5}$ & $\mathrm{Na}_{2} \mathrm{O}_{5}$ & $\mathrm{~K}_{2} \mathrm{O}$ & LOI & Total \\
\hline A & 23.30 & 5.31 & 3.48 & 61.18 & 0.98 & 1.22 & 0.16 & 0.76 & 1.86 & 1.85 & 97.82 \\
\hline B & 22.28 & 5.71 & 3.61 & 61.21 & 0.99 & 0.54 & 0.16 & 0.89 & 1.44 & 1.83 & 97.86 \\
\hline C & 22.42 & 6.03 & 3.81 & 61.53 & 1.27 & 0.31 & 0.16 & 0.19 & 1.09 & 1.80 & 97.98 \\
\hline D & 21.94 & 5.73 & 3.68 & 63.40 & 1.04 & 0.33 & 0.21 & 0.13 & 0.96 & 1.96 & 99.10 \\
\hline
\end{tabular}

Table 2: Estimated mineral composition of Clinker samples using Bogue calculation

\begin{tabular}{|c|c|c|c|c|c|c|}
\hline \multirow[t]{2}{*}{ Samples } & \multicolumn{6}{|c|}{ Calculated mineral composition (percent weight) } \\
\hline & $\mathrm{C}_{3} \mathrm{~S}$ & $\mathrm{C}_{2} \mathrm{~S}$ & $\mathrm{C}_{3} \mathrm{~A}$ & $\mathrm{C}_{4} \mathrm{AF}$ & Total & $\mathrm{CaO}_{\text {free }}$ \\
\hline A & 24.36 & 8.61 & 10.59 & 28.58 & 72.14 & 4.62 \\
\hline B & 41.34 & 30.40 & 9.45 & 10.99 & 92.18 & 1.23 \\
\hline $\mathrm{C}$ & 37.85 & 33.92 & 9.96 & 11.59 & 93.32 & 3.64 \\
\hline D & 48.32 & 25.65 & 9.51 & 11.20 & 94.68 & 6.49 \\
\hline
\end{tabular}

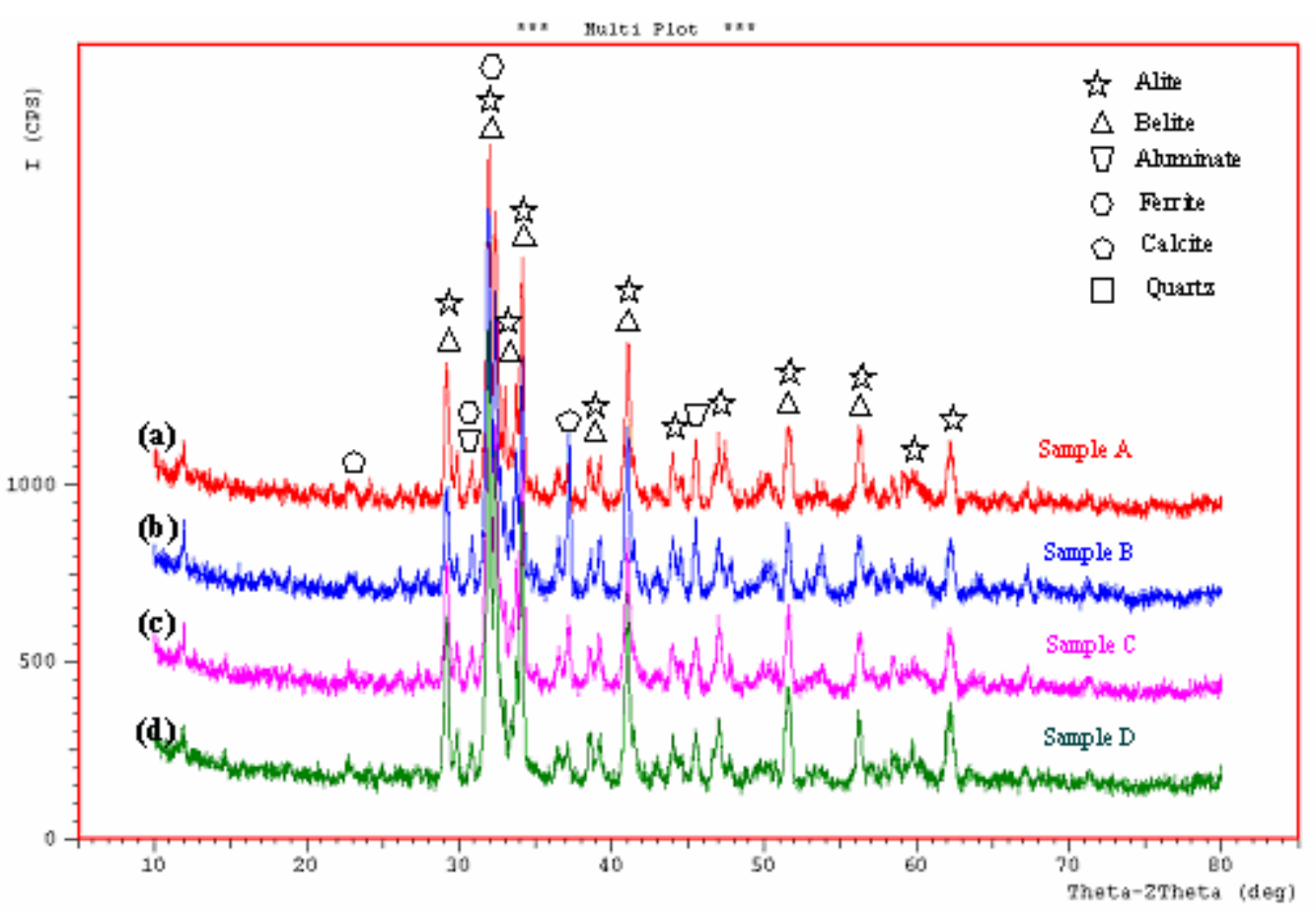

Fig. 1: Diffraction pattern for four Clinker samples

Furthermore, diffraction pattern at the angle $2 \theta \approx$ $31^{0}$ indicating the diffraction angle for belite which had PDF No. (31-298) and (24-234). These belite structures have same orthorhombic crystal structure but different lattice structure which is primitive and end-centred lattice. While, $\alpha$ '-belite with PDF No. (36-642) have orthorhombic crystal structure.

Figure 3 shows the diffraction peak at angle range $31^{0}-34^{0}$. Diffraction pattern at the angle $2 \theta \approx 32^{0}-34^{0}$ shows the highest intensities and overlapping phase at narrow range. To specify the analysis, small range of data peak of diffraction had analysed using XRD software for this range as shown in Fig. 3.

At this range, mineral phases existed are identified as alite, belite, aluminate and ferrite. According to diffraction data identified through the software, three types of alite occur in the diffraction angle $2 \theta \approx 32^{0}$ which is PDF File No. (16-0407), (31-0301), (16-0406). These three types of alite have different crystal structures which are orthorhombic, anorthic (triclinic) and rhombohedra. 


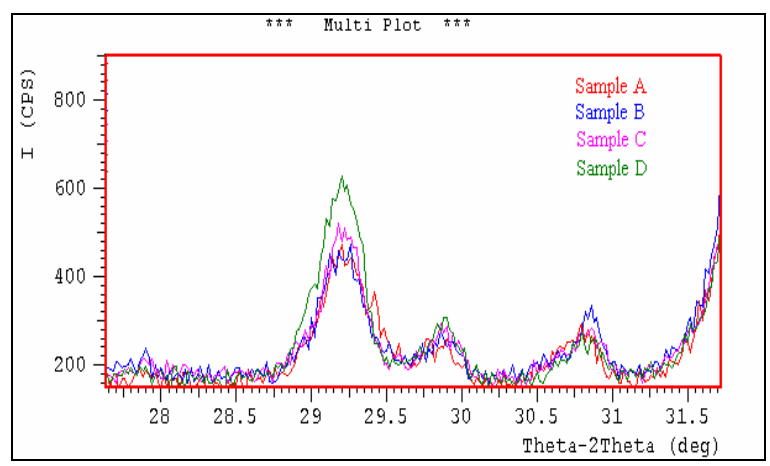

Fig. 2: $\quad$ Diffraction peak for angle range $28^{\circ}-31^{\circ}$

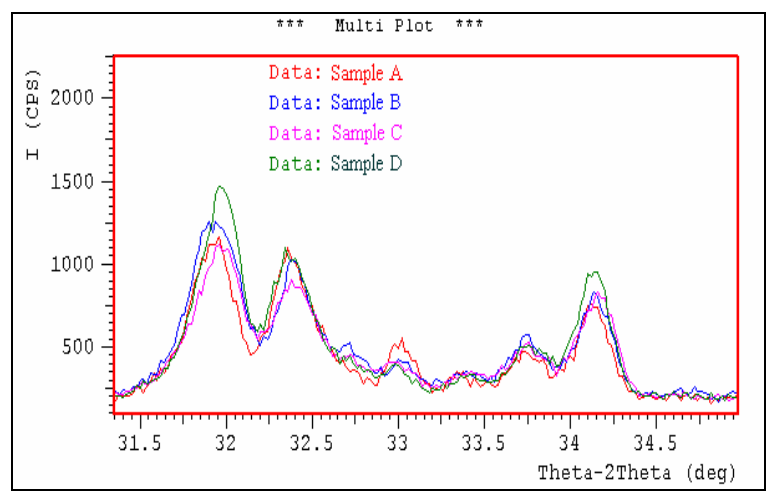

Fig.3: Diffraction peak for angle range $28^{\circ}-31^{\circ}$

While, four types of belite detected approximately at same diffraction which are PDF File No. (23-1042), (33-0302), (31-0298) and one polymorph of belite which is $\alpha$-belite (36-0642) and have orthorhombic crystal structure. Other three types of belite also have different crystal structures which are hexagonal, monoclinic and orthorhombic.

One type of aluminate existed in this angle of diffraction indicated by PDF No. (33-0251) is having orthorhombic crystal structure. For ferrite phase, there is only one type existed in this angle which have PDF No. (30-0226) or sometimes known as Brownmillerite minerals. In contrast, aluminate and ferrite did not existed in this angle except in the samples A and B only.

For the diffraction angle $2 \theta \approx 32.4^{0}$, four types of alite were detected with PDF No. (16-0407), (31-0301), (16-0406) and (22-0539). This alite minerals is known as ankinite. These all types of alite have different crystal structures which are orthorhombic, anorthic (triclinic), rhombohedra and monoclinic. While, all six types of belite occurs in this angle which are having PDF No. (33-0302), (31-0298), (31-0299), two polymorph of belite which are $\alpha$-belite with PDF No. (36-0642), (33-0303) and also $\gamma$-belite (24-0034). First

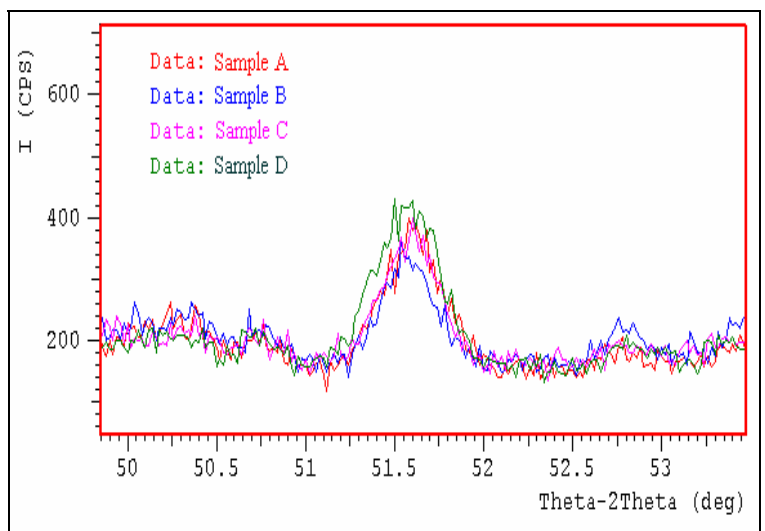

Fig.4: Diffraction peak for angle range $51^{\circ}-52^{\circ}$

three types of belite have monoclinic and orthorhombic crystal structure.

Three types of alite at diffraction angle $2 \theta \approx 33^{0}$ indicated by PDF No. (16-0407), (31-0301) and (220539) for Rankinite mineral. These types of alite mineral also have polymorphism in their crystal structure which is similar with alite present at angle $2 \theta$ $\approx 32.4^{0}$.

While, four types of belite are found here and these are indicated by PDF No. (23-1042), (24-0234), (310299) and one polymorph of belite which is $\alpha$ '-belite with PDF No. (36-0642). In addition, two types of aluminate existed in this angle which are presented by PDF No. (32-0148) and (32-0150). At this angle, hematite $\left(\mathrm{Fe}_{2} \mathrm{O}_{3}\right)$ that is not fully converted to ferrite will be existed here especially before clinkering process completed in sample A.

For diffraction angle $2 \theta \approx 33.7^{0}$, three types of alite that similar with the alite phase in the diffraction angle $2 \theta \approx 32^{0}$ are indicated by PDF File No. (16-0407), (310301), (16-0406). Interestingly, only one type of belite phase existed at this angle indicated by PDF No. (310299). While, for aluminate phase, there are two types of phases existed indicated by PDF No. (32-148) and (33-0251). For ferrite phase, there are both types existed in this angle which indicated by PDF No. (300226) or known as Brownmillerite minerals and PDF No (35-0040). On contrary, aluminate and ferrite did not existed in this angle except in the samples $\mathrm{A}$ and $\mathrm{B}$.

Furthermore, for the diffraction angle at $2 \theta \approx 34.2^{0}$, only one type of alite identified with PDF No. (310301). While, two types of belite phases which is $\alpha$ 'belite; PDF No. (36-0642) and $\gamma$-belite; PDF No. (240034), existed in this angle. 
At the diffraction angle $2 \theta \approx 51^{0}-52^{0}$, there are two types of belite mineral phases indicated by PDF No (33-302) and $\gamma$-belite (24-0034) in sample A. Interestingly, alite mineral phases that indicated by PDF No. (31-0301) existed in samples C and D are found not existed in the sample A. It is obvious that $\gamma$-belite maybe transformed to alite mineral after clinkering process has completed.

\section{CONCLUSION}

Transformation of mineral phases is found affected by different temperature during cement production. There is a different type of mineral phases are observed in approximately at the same angle. Clinkering process affect the transformation of mineral phases which have similar element but different phase in the clinker. Alite and belite mineral phases show a polymorphism behaviour rather than aluminate and ferrite.

\section{ACKNOWLEDGEMENTS}

We would like to acknowledge CIMA Limited, Malaysia for the contribution of clinker samples and KUKUM for providing the Short-Term Grant to support this project.

\section{REFERENCES}

1. Tylor, H.F.W., 1997. Cement Chemistry. Thomas Telford Publishing, London.

2. Emmanualson, A., S. Hansen and E. Viggh, 2003. A comparative study of ordinary and mineralised portland cement clinker from two different production Unit. Part I: Composition and Hydration of the Clinkers, Concrete and Cement Research, 33: 1613-1621.

3. Feret, B. and C.F. Feret, 1999. C $^{\mathrm{em}}$ QUANT $^{\circledR}$ software mathematical modeling in quantitative phase analysis of Portland cement. Cement and Concrete Research, 29: 1627-1633.

4. Idris, M.S., 2006. Kajian Pencirian Mikrostruktur Klinker Semasa Pengeluaran Simen. Unpublished MSc Thesis, Pusat Pengajian Kejuruteraan Bahan, Kolej Universiti Kejuruteraan Utara Malaysia.

5. de Noirfontainea, M.-N., F. Dunstetter, M. Courtial, G. Gasecki and M. Signes-Frehel, 2006. Polymorphism of Tricalcium Silicate, The Major Compound of Portland Cement Clinker 2. Modelling Alite for Rietveld Analysis. An Industrial Challenge Cement and Concrete Research, 36: 54- 64. 